\title{
Household food (in)security and nutritional status of urban poor children aged 6 to 23 months in Kenya
}

\author{
Maurice Mutisya ${ }^{1,2^{*}}$, Ngianga-bakwin Kandala ${ }^{3,4}$, Moses Waithanji Ngware ${ }^{1,2}$ and Caroline W. Kabiru ${ }^{1,2}$
}

\begin{abstract}
Background: Millions of people in low and low middle income countries suffer from extreme hunger and malnutrition. Research on the effect of food insecurity on child nutrition is concentrated in high income settings and has produced mixed results. Moreover, the existing evidence on food security and nutrition in children in low and middle income countries is either cross-sectional and/or is based primarily on rural populations. In this paper, we examine the effect of household food security status and its interaction with household wealth status on stunting among children aged between 6 and 23 months in resource-poor urban setting in Kenya.

Methods: We use longitudinal data collected between 2006 and 2012 from two informal settlements in Nairobi, Kenya. Mothers and their new-borns were recruited into the study at birth and followed prospectively. The analytical sample comprised 6858 children from 6552 households. Household food security was measured as a latent variable derived from a set of questions capturing the main domains of access, availability and affordability. A composite measure of wealth was calculated using asset ownership and amenities. Nutritional status was measured using Height-for-Age (HFA) z-scores. Children whose HFA z-scores were below -2 standard deviation were categorized as stunted. We used Cox regression to analyse the data.
\end{abstract}

Results: The prevalence of stunting was $49 \%$. The risk of stunting increased by $12 \%$ among children from food insecure households. When the joint effect of food security and wealth status was assessed, the risk of stunting increased significantly by 19 and $22 \%$ among children from moderately food insecure and severely food insecure households and ranked in the middle poor wealth status. Among the poorest and least poor households, food security was not statistically associated with stunting.

Conclusion: Our results shed light on the joint effect of food security and wealth status on stunting. Study findings underscore the need for social protection policies to reduce the high rates of child malnutrition in the urban informal settlements.

Keywords: Food (in)security, Urban poor, Child health, Stunting, Malnutrition, Wealth status, Nairobi, Kenya

\section{Background}

A vast pool of evidence shows that food security is associated with a number of human and economic development outcomes $[1,2]$. In light of the high burden of malnutrition and its consequences, the Sustainable Development Goals (SDGs) highlight food security as a human right

\footnotetext{
* Correspondence: mmutisya@aphrc.org

'African Population and Health Research Center, P.O Box 10787 - 00100,

Nairobi, Kenya

${ }^{2}$ University of the Witwatersrand, School of Public Health, 27 St Andrews

Road, Johannesburg Parktown 2193, South Africa

Full list of author information is available at the end of the article
}

that needs to be addressed with urgency [3]. Despite this recognition, millions of people in low and low middle income countries suffer from extreme hunger and malnutrition [1]. Household food insecurity is associated with poor nutritional health $[2,4]$. Among children, poor nutritional status has negative consequences on growth and development, especially during the early years of life [5]. While poor nutrition status in children includes over nutrition, it often refers to cases of undernutrition [6]. Undernutrition refers to deficiency of protein energy, micronutrients and vitamins as well as minerals essential for growth. 
Globally, there has been a decline in malnutrition levels from the 1990s; however, the levels in sub Saharan Africa have remained high $[7,8]$. Close to $90 \%$ of stunted (a long term measure of malnutrition) children in the world live in Africa and Asia, with the prevalence of stunting in Africa being $36 \%$ in 2011 [9]. In Kenya the prevalence of stunting was $26 \%$ in 2014 [10]. In urban poor settings in low and middle income countries where few households can produce their own food, the prevalence of stunting may be even higher. In informal settlements in Nairobi, for example, $60 \%$ of children below 5 years were stunted in 2010 as compared to $17 \%$ for the whole of Nairobi $[10,11]$.

Food security and nutrition are different concepts that are intricately linked resulting to some researchers to apply the two concepts interchangeably. However, food security is a means to nutritional status, and is necessary but not sufficient for nutrition [12]. There exists an extensive body of literature on nutritional status among under-five children and women [1, 13]. The focus on children is because their physiology, growth and development are sensitive to both adequate food (food secure) and nutrition $[11,14,15]$. Further, childhood malnutrition contributes to nearly one third of under-five deaths in the world and up to $11 \%$ of Disability Adjusted Life Years (DALYS), with $80 \%$ of the deaths occurring in low income countries [13].

The first 1000 days of a child life (from conception to the second birthday) have been noted to be very crucial $[16,17]$. This period is characterized by rapid brain growth [18]. Therefore, any disruptions, especially occasioned by malnutrition, during this period can have both short and long term effects on education, health and productivity [8].

Research in high income countries shows that food insecurity is associated with poor health outcomes across the population $[19,20]$. A study of eight low income countries found food insecurity to be associated with low heightfor-age (stunting ) Z-scores [21]. In Canada, food insufficiency was found to be associated with poor self-reported health status [20]. This highlights the importance of food security as a determinant of individual physical, social and mental wellbeing.

Research on the association between food insecurity and malnutrition has produced mixed results. While some studies have found a positive relationship [14, 22, 23] others have found no association or even a negative one [24]. Moreover, the existing evidence on food security and nutrition in children in low and middle income countries is either cross-sectional and/or is based primarily on rural populations. Using longitudinal data collected between 2006 and 2012, we model the relationship between food insecurity and nutrition (measured by stunting) controlling for other covariates among children aged between 6 and 23 months in two urban informal settlements in Nairobi,
Kenya. Fotso et al. [11] drew on the same dataset to analyse the effect of poverty on child growth using multi-level modelling. The main outcome was stunting measured by z-scores. Poverty status was measured using several indicators including asset index, household expenditure, food security index and self-reported poverty (based on a subjective index). Overall, the food security index was associated with child stunting for ages 6 to 11 months. The household asset index was also a strong predictor of stunting, and the effect increased with increased age of the child. The study however, modelled the different poverty indicators separately/independently. By so doing, they assumed the different poverty indicators affect stunting in isolation. In addition, the effect of food insecurity on children is hypothesised to take place from the point of introduction to complementary feeding, that is, from 6 months, yet in their study they included all children from birth (age 0). Moreover, as a longitudinal study, which was subject to attrition, it was unusual to use a multi-level model. This model does not take into consideration the loss of follow-up and the time amount of time those lost to follow-up have contributed (exposure duration) to the study, which may have resulted in an underestimate of the effect of the poverty measures on child nutrition.

To address the limitations of the Fotso et al. [11] study, in the current study we used survival analysis, which takes care of the exposure period, hence reducing the bias due to attrition. As food security, a proximate determinant of child nutrition, is likely to be strongly influenced by poverty [13], we interacted the asset wealth index with food security status in order to establish whether the effect of food security differs by the levels of asset wealth status. We therefore hypothesise that 1) household food security is associated with the nutrition status of children aged between 6 and 23 months; and 2) the effect of household food security on stunting does not vary by household wealth status, a proxy measure of poverty.

\section{Methods}

\section{Study setting}

The study was conducted in two informal settlementsKorogocho and Viwandani-located in Nairobi, Kenya. The two study sites are part of the Nairobi Urban Health and Demographic Surveillance System (NUHDSS). The NUHDSS was initiated in 2002 to collect health and demographic statistics from an urban poor population. From 2003, the NUHDSS framework has provided opportunities for nesting studies, including the current study. For detailed description of the NUHDSS see Beguy et al. [25]. 


\section{Data and data source}

Data for this study come from the Maternal and Child Health (MCH) study (2006-2010), which was a sub-study of the broader Urbanization, Poverty and Health Dynamics project, and the INDEPTH Vaccination Project (IVP) study $(2011$ - 2013). The latter was a continuation of the $\mathrm{MCH}$ study. The $\mathrm{MCH}$ study was nested within the NUHDSS framework. The project targeted all women of reproductive health residing in the two study communities who gave birth between the duration of study-2006 to 2013. Under the $\mathrm{MCH}$ project, mothers and their newborns were recruited upon delivery. The mothers and their children were then followed prospectively until the child was 5 years or until when they exited from the study either through death or out migration. Data were collected on the mother's social demographic characteristics, her health seeking behaviour during and after delivery, feeding practices, immunization of the child as well as the anthropometric measures for both the child and mother. Upon recruitment, three follow-up visits, in this study referred to as updates, were made each calendar year. The following variables were extracted from two data sets: 1 ) Child characteristics that include date of birth, date of recruitment and subsequent visits, gender of the child, immunization, anthropometric measures, and birth weight and; 2) maternal characteristics that included the mother age at birth, parity, education level and health seeking behaviour. By 2013, 7452 children had been recruited to the study. During analysis, we excluded children with missing information on stunting between the ages 6 and 23 as well as those who were lost to follow-up before they attained the age of 6 months. The final sample consisted of 6858 children contributing to 101,686 person months.

\section{Variables and measurement}

The dependent variable is stunting, which is Height for Age (HFA). Stunting is used here because it is a measure of long term food deprivation (chronic malnutrition) and illness making it a good indicator of child nutrition [26]. We calculated z-scores for the HFA using the 'WHO Child Growth Charts and WHO Reference 2007 Charts' for children aged up to 2 years. This was suitable because analysis was restricted to children aged between 6 and 24 months. The entry age was set at 6 months, which marks the end of exclusive breastfeeding and introduction to complimentary feeding. The Z-scores show the number of standard deviations of a child on a particular anthropometric measure in relation to a mean or median value. In this regard, those with z-scores of 2 standard deviations of height for age below the WHO reference median were categorized as stunted. Those with a score of above 2 standard deviations were categorized as normal (not stunted) [27]. Child anthropometric measures were obtained during each visit and therefore, stunting was calculated at the each points of visit.

The primary independent variable was household food security status. Food security exists "when all people at all times have access to sufficient, safe, nutritious food to maintain a healthy and active life" [28]. Food security status was computed from a set of questions that captured the domains of food access as described in Radimer framework [29]. The questions assessed the frequency in the 30 days preceding the survey with which households: did not have adequate food; were worried about food availability; lacked enough money to purchase food; and children and adults had to forgo food for a whole day because there was not enough food. The response were coded as either ' $0=$ never true,' ' $1=$ sometimes true' and ' $2=$ often true.' The respondent to the food security component was the household head who in his or her absence, the spouse or someone who had enough information and was credible enough was interviewed. Responses were recoded into binary responses: 'often true' were coded as ' 1 ' and the rest ' 0 ' and as described by [30]. We tested for agreement between the items and found a Cronbach's Alpha of 0.72, indicating a good item reliability [31]. A composite score was generated by summing the items and categorized as $1=$ food secure (score of 0 ); 2 = moderate food insecure (score of 1 or 2 ); and 3 = severely food insecure (score of more than 2).

The second independent variable was the household asset wealth index, a latent variable computed from a composite measure of household assets and amenities. Principal Component Analysis (PCA) was used to reduce the multidimensional nature of the data to a single score that was categorized into three groups: Poorest, middle poor and least poor [32].

\section{Statistical analysis}

Data were managed and analysed in STATA 13.1. Both descriptive and inferential statistics were used for analysis. Frequencies and percentages were computed to describe the key socio-demographic characteristics of the study sample. In addition, descriptive statistics were used to estimate the prevalence of stunting in the sample. As multiple measures on stunting exist for each child, the exposure, which is the age of the child, was calculated for each visit. We used Cox regression models to estimate the survival time from age six to first stunting and to assess whether the survival time significantly varied by household food security status. The Cox regression models allowed us to control for other known determinants of stunting. In our study we restricted analysis to time to the first stunting. We tested the assumption of proportional hazard in the Cox regression, which is that the hazards are constant between the food security status and wealth status categories being compared. To test this assumption, we used Kaplan-Meier Curves and the 
$\log$ rank test. We also tested the assumption by interacting survival time with time varying covariate. Different Cox regression models were fitted: 1 ) unadjusted models with the key independent variables that included food security and household; 2) adjusted Cox regression with two main covariates-food security and wealth index; 3 ) a fully adjusted model, including all the covariates; and 4) a fully adjusted model with all covariates and the interaction between wealth index (poorest, middle poor and least poor) and food security status. The latter model was used to determine whether the effect of food security on stunting was the same across the wealth quintiles.

For the Cox regression model, age in months was the main dependent variable with a dummy variable indicating whether the child is stunted or not. Each child was observed from birth between 2006 and 2013 until either the child was stunted, was censored due to loss of follow-up, out-migration or end of the follow-up for the child who aged above 23 months.

\section{Ethical clearance and informed consent}

Ethical clearance for both the $\mathrm{MCH}$ and IVP studies were granted by the Kenya Medical Research Institute (KEMRI). In addition, ethical clearance to use the data for secondary analyses was obtained from the University of the Witwatersrand, Human Research Ethics Committee and AMREF Kenya. Informed consent was obtained from all individual participants included in the study. All procedures were conducted in accordance with the ethical standards of the institutional and/or national research committee and with the 1964 Helsinki declaration and its later amendments or comparable ethical standards.

\section{Results}

Table 1 presents the background characteristics of the study sample at the point of entry into the study (about age of 6 months). The table also shows the proportion of stunted children for each variable category. Overall, the prevalence of stunting among children aged between 6 and 23 months in the study areas was about $49 \%$. The study sample consisted of nearly an equal number of male and female children, however, the proportion of stunted male children (54\%) was higher than females (44\%). Although a slightly higher proportion of children lived in Korogocho (53 \%) than Viwandani, a greater proportion of children in Viwandani (52 \%) were stunted compared with Korogocho (45 \%).

Two key variables were time variant-food security and household asset wealth index. The two variables were calculated for all the households in the two study sites and thereafter merged with the data used in this analysis. At entry, $50 \%$ of children were from moderately food insecure households, while $22 \%$ were from severely food insecure households. The proportion of stunted children increased with food insecurity. There was a 7 and 12 percentage point increase in stunting between the food secure and either moderate and severely food insecure households respectively. In terms of wealth index, most of the households were ranked poorest at entry time in relation to the overall population in the two study sites. Stunting was highest (53\%) among poorest households and lowest (47 \%) among the least poor households.

Mother's education and parity were significantly associated with stunting. Overall, three quarters of the mothers had at least primary level education. The proportion of children who were stunted was higher (52\%) among mothers with lower levels of education (primary or less) compared with at least secondary education (43\%). Stunting was more common among mothers with a parity of five or more $(54 \%)$ compared with those with a parity of below five.

\section{Food security, wealth status and stunting}

Table 2 shows levels of stunting stratified by both household food security and asset wealth status. The results show disproportionate stunting of children across wealth index. The proportion of stunted children was higher among the poorest households than among the least poor. In addition, within each wealth tertile, stunting was higher among children from food insecure households than those from food secure. Stunting was highest among severely food insecure households ranked in the poorest tertile and lowest among food secure households in the middle wealth tertile. These results illustrate the interactive effect of household food security and wealth status on child nutrition.

Figure 1 shows the survival curves for both food security and asset wealth index. Children from the poorest and food insecure households had a lower survival time. By 23 months close to half of the children from poor and severely food insecure households were stunted. The food security survival pattern is consistent with descriptive statistics presented in Tables 1 and 2. The wealth index showed no clear difference between the middle poor and the least poor. However, the poorest, had a lower survival than the middle and least poor.

Figure 2 shows the levels of stunting by age of the child in months. Stunting was highest between 10 and 15 months, peaking at around 12 months of age. That is, from 6 months, age at which complimentary feeding is introduced, there was a sharp increase in the proportion of stunted children until 15th month and thereafter declines to slightly about $10 \%$ by month 23 .

Using Cox regression models, we further explored the relationship between household food security and stunting (Table 3). Three models are presented: Model 1, with bivariate associations for food security, wealth status, study site and gender of the child; Model 2 includes 
Table 1 Background characteristics of the study sample at entry and levels of stunting $(n=6858)$

\begin{tabular}{|c|c|c|c|c|}
\hline \multirow[t]{2}{*}{ Characteristic } & \multicolumn{2}{|c|}{ Number } & \multicolumn{2}{|c|}{ Percentage } \\
\hline & Total & Stunted & Sample & Stunted \\
\hline Overall & 6858 & 3349 & - & 48.83 \\
\hline \multicolumn{5}{|l|}{ Child sex ${ }^{* *}$} \\
\hline Male & 3462 & 1858 & 50.48 & 53.67 \\
\hline Female & 3396 & 1491 & 49.52 & 43.90 \\
\hline \multicolumn{5}{|l|}{ Food security ${ }^{* *}$} \\
\hline Food secure & 1930 & 823 & 28.14 & 42.64 \\
\hline Moderate & 3432 & 1708 & 50.04 & 49.77 \\
\hline Food insecure & 1496 & 818 & 21.81 & 54.68 \\
\hline \multicolumn{5}{|l|}{ Wealth index } \\
\hline Poorest & 2778 & 1466 & 40.51 & 52.77 \\
\hline Middle & 2125 & 970 & 30.99 & 45.65 \\
\hline Least poor & 1955 & 913 & 28.51 & 46.70 \\
\hline \multicolumn{5}{|l|}{ Mother education ${ }^{* *}$} \\
\hline $\begin{array}{l}\text { Incomplete primary/no } \\
\text { education }\end{array}$ & 1902 & 991 & 27.73 & 52.10 \\
\hline Completed primary & 3251 & 1621 & 47.40 & 49.86 \\
\hline Secondary plus & 1705 & 737 & 24.86 & 43.23 \\
\hline \multicolumn{5}{|l|}{ Birth weight ${ }^{* *}$} \\
\hline Below 2500 & 346 & 166 & 5.05 & 47.98 \\
\hline $2500-2900$ & 1007 & 548 & 14.68 & 54.42 \\
\hline$=>3000$ & 3817 & 1795 & 55.66 & 47.03 \\
\hline No birth weight record & 1688 & 840 & 24.61 & 49.76 \\
\hline \multicolumn{5}{|l|}{ Breast feeding } \\
\hline Yes & 72 & 41 & 1.05 & 56.94 \\
\hline Introduced to foods & 6786 & 3308 & 98.95 & 48.75 \\
\hline \multicolumn{5}{|l|}{ Parity ${ }^{*}$} \\
\hline 1 & 2097 & 962 & 30.58 & 45.88 \\
\hline 2 & 2016 & 982 & 29.40 & 48.71 \\
\hline 3 & 1227 & 606 & 17.89 & 49.39 \\
\hline 4 & 683 & 346 & 9.96 & 50.66 \\
\hline 5 plus & 835 & 453 & 12.18 & 54.25 \\
\hline \multicolumn{5}{|l|}{ Study site } \\
\hline Korogocho & 3613 & 1894 & 52.68 & 52.42 \\
\hline Viwandani & 3245 & 1455 & 47.32 & 44.84 \\
\hline \multicolumn{5}{|l|}{ HHH Education ${ }^{* *}$} \\
\hline No education & 291 & 151 & 4.24 & 51.89 \\
\hline Primary & 4172 & 2117 & 60.83 & 50.74 \\
\hline Secondary \& above & 2393 & 1081 & 34.92 & 45.14 \\
\hline \multicolumn{5}{|l|}{$\mathrm{HHH}$ sex } \\
\hline Female & 1606 & 797 & 23.42 & 49.63 \\
\hline Male & 5225 & 2552 & 76.58 & 48.59 \\
\hline
\end{tabular}

Table 1 Background characteristics of the study sample at entry and levels of stunting $(n=6858)$ (Continued)

\begin{tabular}{llll}
\hline Mean mother age $^{a}$ & 6558 & $25.04(5.92)$ & $24.73(5.86)$ \\
Mean HHH age $^{a}$ & 6558 & $34.49(9.65)$ & $33.92(9.63)$ \\
Average HH size $^{a}$ & 6558 & $4.67(1.98)$ & $4.64(1.90)$
\end{tabular}

Significant at ${ }^{*} p<0.05 ;{ }^{* *} p<0.01$ when testing difference in the proportion of children stunted by each variables; $\mathrm{HH}=$ Household; $\mathrm{HHH}=\mathrm{HH}$ head; ${ }^{\mathrm{a}}$ Mean and standard deviations reported

both food security and wealth index; and a full model (Model 3) which includes Model 2 and controls for other known determinants of stunting. From the bivariate results (Model 1), household security and asset wealth index were significantly associated with stunting. That is, the hazards of a child being stunted if he or she was from a moderate and severely food insecure household increased by $16 \%$ and $23 \%$ compared with children from food secure household. Improved household asset wealth index was associated with lower risk of being stunted. Children from middle (HR: 0.86, CI: 0.79-0.93) and least poor (HR: 0.89, CI: 0.82-0.96) households had significantly lower risk of being stunted compared to those from the poorest households.

After adjusting for the wealth index (M2), the association between food security and stunting remained positive and significant. In this model, children from the severely food insecure households were $21 \%$ (HR: 1.21, CI: 1.09-1.33) more likely to be stunted than those from food secure households. The risk of stunting among moderately food insecure households significantly increased by $15 \%$; while the effect of wealth index on stunting was attenuated and was only significant for those in the middle category. That is, though the middle poor and least poor had a reduced risk of stunting, only the risk among middle poor remained significant at $95 \%$ level of significance. The third model (M3) included both food security and wealth status

Table 2 Proportion of stunted children by food security status and asset wealth index at the point of stunting

\begin{tabular}{llccc}
\hline & Number & \% of sample & \% stunted & $P$-Value \\
\hline Poorest - overall & 2815 & 41.0 & 52.50 & 0.26 \\
Food secure & 469 & 20.2 & 49.5 & \\
Moderate & 1572 & 94.9 & 52.5 & \\
Food insecure & 774 & 26.9 & 54.3 & \\
Middle poor - overall & 2072 & 30.2 & 46.04 & 0.01 \\
Food secure & 554 & 23.9 & 40.8 & \\
Moderate & 1009 & 60.9 & 46.6 & \\
Food insecure & 509 & 17.7 & 50.7 & \\
Least poor - overall & 1971 & 28.7 & 46.52 & 0.08 \\
Food secure & 926 & 39.9 & 44.3 & \\
Moderate & 859 & 51.8 & 47.6 & \\
Food insecure & 186 & 6.5 & 52.7 & \\
\hline
\end{tabular}



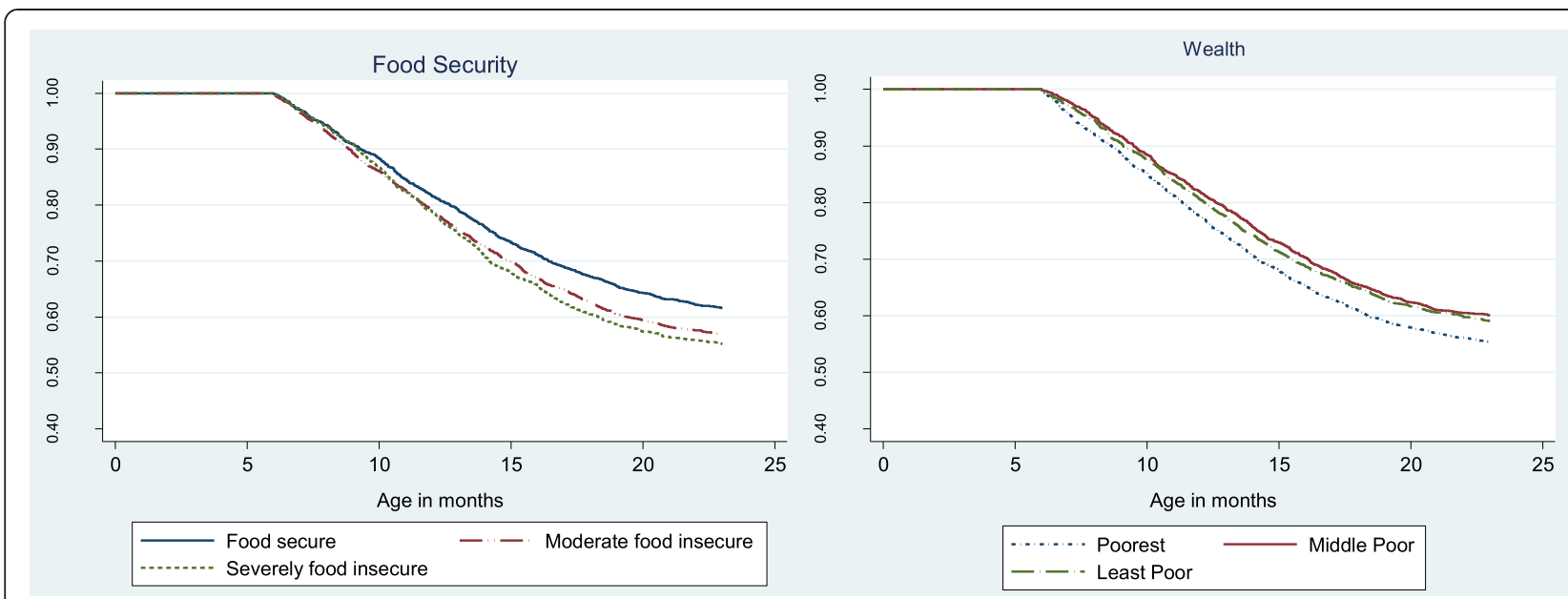

Fig. 1 Food security and wealth status Kaplan Meir survival curves

controlling for a number of characteristics. Food security in this model remained significant, and was in the same directions as model 1 and 2, while the association between stunting and wealth status was stronger and significant for the middle and least poor category. Other factors significantly associated with stunting in model three were breastfeeding and gender of the child. That is, children who had been introduced to complimentary foods and girls were 37 and $20 \%$ less likely to be stunted compared to those who were breastfeeding and boys respectively.

We hypothesized that household food security interacts with asset wealth index to influence stunting. That is, wealth index modifies the effect of food security on stunting. To assess this interaction, we fitted a full model (similar to Model 3) while interacting food security and wealth status (Fig. 3). In the model, we alternated the reference category to food secure households in each wealth status. That is, in the poorest wealth category, the reference group was those households in this category that were food secure, likewise in the least poor wealth category, the reference group was those households in this category that were food secure. In this regard, the same model was run three times with the reference category changing for each wealth category. By

Table 3 Bivariate and multiple Cox regression hazard ratio on stunting $(n=6858)$

\begin{tabular}{|c|c|c|c|c|c|c|c|c|c|}
\hline \multirow[t]{2}{*}{ Variable } & \multicolumn{3}{|c|}{ M1: Bivariate } & \multicolumn{3}{|c|}{ M2: Adjusted for WI } & \multicolumn{3}{|c|}{ M3: Other covariates } \\
\hline & $\overline{\mathrm{HR}}$ & \multicolumn{2}{|c|}{$95 \% \mathrm{Cl}$} & $\overline{\mathrm{HR}}$ & \multicolumn{2}{|c|}{$95 \% \mathrm{Cl}$} & $\overline{\mathrm{HR}}$ & \multicolumn{2}{|c|}{$95 \% \mathrm{Cl}$} \\
\hline \multicolumn{10}{|l|}{ Food security } \\
\hline Food secure & 1 & & & 1 & & & 1 & & \\
\hline Moderate & $1.16^{* *}$ & 1.07 & 1.26 & $1.15^{* *}$ & 1.05 & 1.25 & $1.12^{* *}$ & 1.02 & 1.22 \\
\hline Food insecure & $1.23^{* *}$ & 1.11 & 1.35 & $1.21^{* *}$ & 1.09 & 1.33 & $1.15^{*}$ & 1.03 & 1.28 \\
\hline \multicolumn{10}{|l|}{ Wealth index } \\
\hline Poorest & 1 & & & 1 & & & 1 & & \\
\hline Middle & $0.86^{* *}$ & 0.79 & 0.93 & $0.87^{* *}$ & 0.80 & 0.94 & $0.82^{* *}$ & 1.02 & 1.22 \\
\hline Least poor & $0.89^{* *}$ & 0.82 & 0.96 & 0.93 & 0.86 & 1.02 & $0.79^{*}$ & 1.03 & 1.28 \\
\hline \multicolumn{10}{|l|}{ Study site } \\
\hline Korogocho & 1 & & & & & & 1 & & \\
\hline Viwandani & $0.85^{* *}$ & 0.79 & 0.91 & & & & 0.95 & 0.86 & 1.04 \\
\hline \multicolumn{10}{|l|}{ Child sex } \\
\hline Male & 1 & & & & & & 1 & & \\
\hline Female & $0.80^{* *}$ & 0.75 & 0.85 & & & & $0.80^{* *}$ & 0.75 & 0.86 \\
\hline
\end{tabular}

WI = Wealth index; Model 1 (M1): Bivariate association; Model 2 (M2): Includes both food security and asset wealth index; Model 3 (M3): Includes model 2 and controls for other covariates: Mother and child characteristics (Age at birth, education level, parity at birth, breastfeeding, birth weight) and Household characteristics (head education, sex, age and size)

Significant at ${ }^{*} p<0.05 ;{ }^{* *} p<0.01$ 


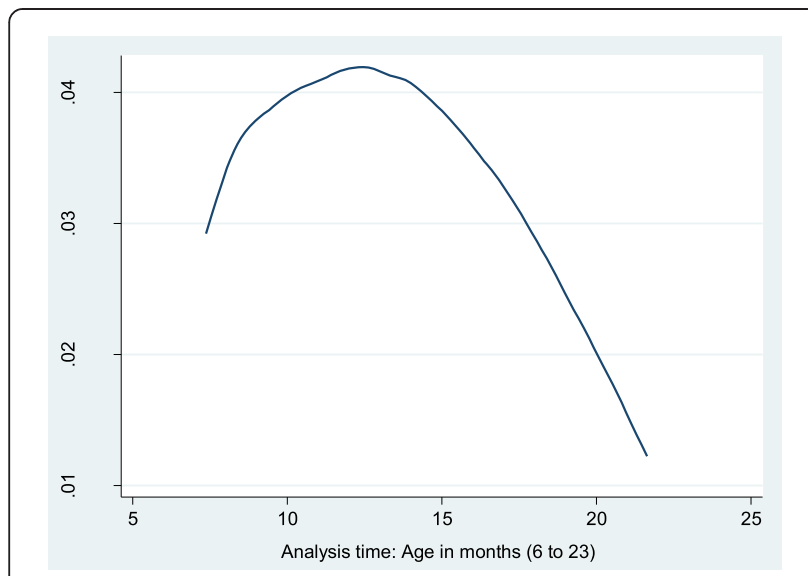

Fig. 2 Cox regression survival curve on hazards of stunting

so doing, one is able to interpret the hazards ratios within each wealth category more objectively.

Overall, within each wealth category, the risk for stunting increased with increasing food insecurity. However, the association was only significant among the middle poor households. Among the poorest households, the effect of food security on stunting was minimal and not statistically significant. Similarly among the least poor, children from households that were moderate or severely food insecure were 12 and $18 \%$ more likely to be stunted, however, this difference was not statistically significant. Among the middle poor households, moderately and severely food insecure households were at significantly higher risk of being stunted compared with food secure ones.

\section{Discussion}

We sought to determine the relationship between household food security and nutritional outcome of children aged between 6 and 23 months living in two informal settlements in Nairobi using a longitudinal dataset. We hypothesized that food insecurity was a key determinant of stunting and that the effect would be modified by household wealth status. The prevalence of stunting in the study sample was high at $49 \%$ and varied by household food security and wealth status. The prevalence of stunting in this study population was higher compared to the national average of $35 \%$ [33].

The effect of food insecurity after controlling for household wealth status and other known determinants of stunting, showed that children from moderately and severely food insecure households were more likely to be stunted than those from food secure households. Models of food security and child nutrition assume that food insecurity results in a lower intake of energy rich foods and nutrients resulting in changes to child health. A recent study by Ali Naser et al. [34] in Malaysia, showed that food insecurity was associated with stunting and underweight. In contrast, in high income countries the reverse is often true. In high income settings, children from food insecure households have an increased risk of being either overweight or obese than those from rich households presumable due to high consumption of energy rich foods coupled with inadequate physical activity and high stress levels [35]. Closer home, a study among orphaned children aged between 6 and 14 years and living in informal settlements of Nairobi, showed that food security was not associated with their nutritional status [36].

While urban populations are often thought to have better social indicators than rural areas, the growth of slums has eroded this advantage [11]. Research evidence has shown that the urban poor are often worse off than their rural counterparts [37, 38]. Recent research shows that urban poor households are becoming increasingly food

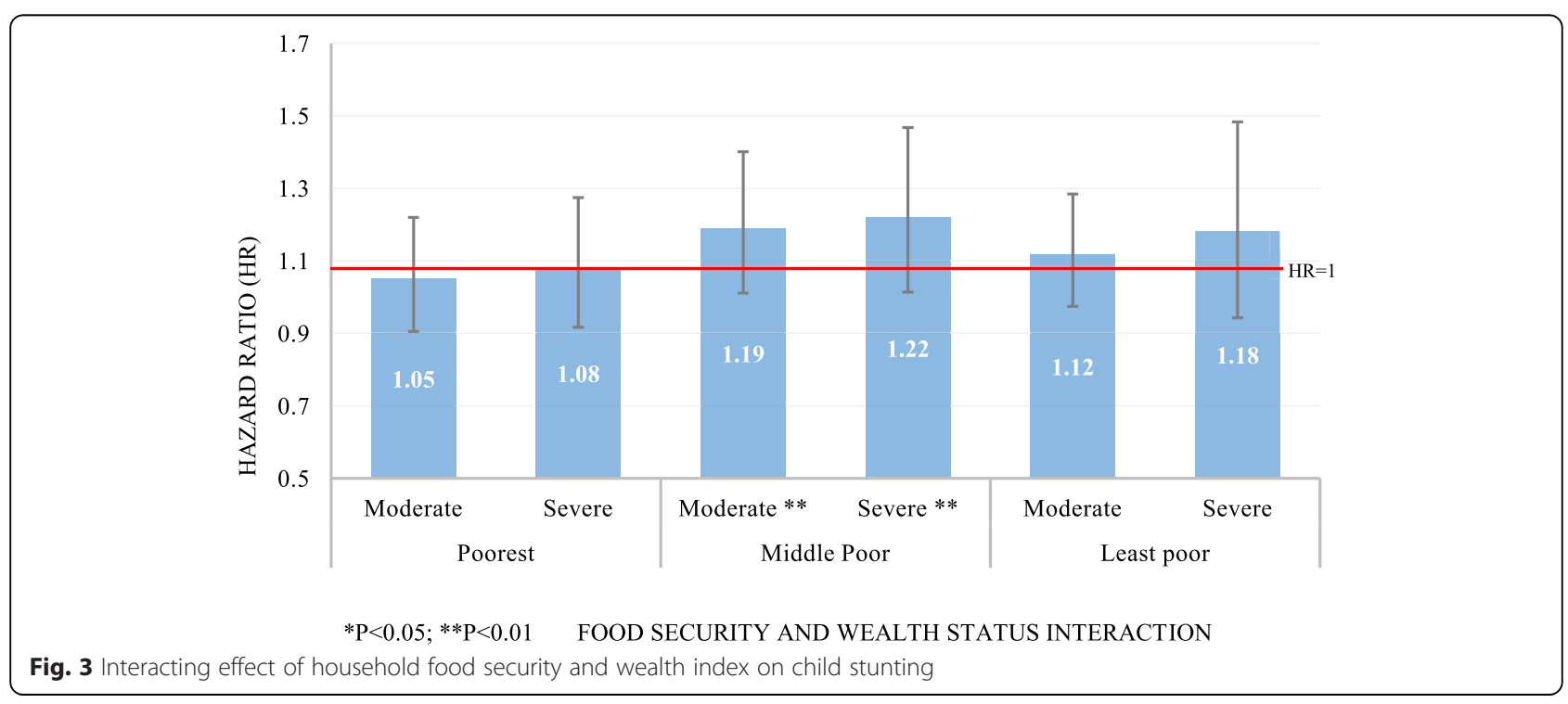


insecure, and in Nairobi, levels of food insecurity are estimated to be as high as $85 \%$ [39]. In the slum setting, food insecurity leads to either decreased food intake, or skipping of meals as well as a lack of nutritious foods to meet the dietary needs of household members. The latter is an important composite for growth especially among children. Studies conducted in the two slums have shown that dietary diversification is rare and that many households consume the same foods for most meals [39]. The positive relationship between food security and child nutrition therefore suggests that poor households are not able to meet their daily dietary needs.

When the results were stratified by wealth tertile (poorest, middle poor and least poor), we observed an increased risk of stunting with increasing food insecurity status. However the differences in stunting by food security status were only significant for the middle poor households. The positive effect of the interaction between food security and wealth status is of interest. While many studies have not explored this relationship, the few that have found a diminished effect of food security controlling for wealth index. For instance, a study in Ghana found that controlling for other covariates minus the wealth status food insecurity to be highly associated with stunting of children aged between 24 and 36 months and not those below 24 months [40]. However, when household wealth status (measured in terms of house quality and asset ownership) was controlled for, the effect became insignificant [40]. Hannum et al. [41] in their study on the effect of poverty, food security and nutritional deprivation on literacy achievement found food insecurity to be positively associated with wealth, with the poorest children likely to be both stunted and underweight. In Brazil, Reis [42] investigated food insecurity and its relationship with income and child health and concluded that food security to be a key in influencing the relationship between income and stunting among poor children.

Food security, poverty and nutritional status are closely intertwined, however, their mechanism of transmission remains unclear [40]. While food insecurity leads to decreased dietary intake, poverty is closely linked with increased levels of food insecurity [13]. Poverty, in this regard, modifies the effect of food insecurity on nutrition. In this study, the effect of food insecurity on stunting was only significant among the middle poor households. We think that this significant result is due to the unstable situation of the middle poor category, who are likely to be in a transition phase and can either fall back to the poorest category or move to the least poor. In this regard, households in the middle wealth status may be more diverse. Moreover, with very limited urban agriculture, households in the study setting depend on out-of-pocket food purchases. In this regard, the poverty status may therefore define the household's access to food. Research evidence on wealth status and obesity shows that in high income countries people from poorer households are more likely to be obese/overweight compared with those from richer households [43]. In high income countries, food insecurity is a measure of poverty, and a strong predictor of overweight, especially among women [44]. In contrast, in low and middle income settings, the poor are less likely to be obese or overweight [43]. Lower levels of obesity and overweight in poorer households in low and middle income countries is often attributed to lower access to energy rich foods and a more physically active lifestyle because the poor have to rely on walking and are more likely to have manual jobs. In the study context, the poorest households irrespective of their food security status, may lack the resources to get enough food for diverse dietary requirements and while the least poor, may have some resources that despite their different food security status guarantees some stability of food. This may be a possible explanation for the lack of statistical significance between the food security categories for the poorest and least poor households.

We interpret the results of this study in light of the following limitations: First, the effect of poverty and food security on nutrition may be more pronounced in older ages than among children. For instance, adult members of the households may miss meals to cope with the existing situations in order to ensure that their children have some food. Saaka et al. [40] found that the relationship between food security and nutritional status was stronger among children aged between 24 and 36 months than those aged between 6 and 23 months. However, the importance of studying those aged between 6 and 23 months is twofold: it is a critical age for growth and in the study context, nearly half of the children are stunted by this age. Secondly, household wealth was assessed using proxy measures-household amenities and asset ownership-due to a lack of accurate information on household incomes and expenditures, which may be better measures of household wealth. Despite these limitations, we utilize longitudinal data from the same children and households providing an opportunity for survival analysis, which is superior to cross-sectional analysis. The longitudinal nature of the data also allowed controlling for fluctuations in household food security and wealth status over time, by modelling the two variables as time variant. By so doing, the probability of reporting a significant effect when there is none was reduced [45].

\section{Conclusion}

The findings of this study show food insecurity is intertwined with malnutrition and poverty. Food insecurity is a public health problem and increasingly becoming a social determinant of health $[46,47]$. Given that food security is a human right [47], there is need for social protection 
policies to reduce the high rates of child malnutrition in the urban informal settlements. Previous efforts by Concern Worldwide in Korogocho slums showed that social protection strategies through cash transfers increased the mean number of meals from 1.6 to 2.5 in a day and decreased prevalence of food insecurity from as high as 97 to $74 \%$ [48]. Further, targeted efforts to address malnutrition among children are imperative. The interventions must take into account high levels of poor sanitation and diarrhoea, which may erode the gains of improved food security among the slums residents [49]. As such, interventions must take a holistic approach in addressing the high levels of malnutrition among the vulnerable urban poor households.

\begin{abstract}
Abbreviations
AMREF: African Medical and Research Foundation; APHRC: African Population and Health Research Center; DALYS: Disability adjusted life years;

HFA: Height-for-age; HR: Hazard ratio; INDEPTH: International Network for the Demographic Evaluation of Populations and Their Health in Developing Countries; IVP: INDEPTH vaccination project; KEMRI: Kenya Medical Research Institute; MCH: Maternal and child health; NUHDSS: Nairobi Urban and Health Demographic Surveillance System; PCA: Principle component analysis; SDGs: Sustainable development goals; WHO: World Health Organization.
\end{abstract}

\section{Competing interests}

The authors declare no conflicts of interest.

\section{Authors' contributions}

MM conducted the literature review, analysis and interpretation of data as well as drafted the initial manuscript; NK contributed to the conceptualisation of the study and reviewed the manuscript for substantial intellectual content. He also guided the methods and analysis; MN contributed to the conceptualisation of the study and reviewed the manuscript for substantial intellectual content. He also provided close supervision throughout the process; CK contributed to the conceptualisation of the study and reviewed the manuscript for substantial intellectual content. She provided guidance on the analysis and the discussion. All authors have read and approved the final manuscript.

\section{Acknowledgements}

We acknowledge the valuable contributions of staff of the NUHDSS and the Maternal Child Health/Indepth Vaccination Projects at the African Population and Health Research Center (APHRC). We particularly acknowledge Martin Mutua who supported the data management. Moreover, we acknowledge the two reviewers, Anu Rammohan and Chrissie Thakwalakwa for their thoughtful comments and suggestions that greatly improved the manuscript. This research was supported by the Consortium for Advanced Research Training in Africa (CARTA). CARTA is jointly led by the African Population and Health Research Center and the University of the Witwatersrand and is funded by the Wellcome Trust (UK) (Grant No: 087547/ Z/08/Z); the Department for International Development (DfID) under the Development Partnerships in Higher Education (DelPHE); the Carnegie Corporation of New York (Grant No: B 8606); the Ford Foundation (Grant No: 1100-0399); Google.Org (Grant No: 191994); Sida (Grant No: 54100029); and MacArthur Foundation Grant No: 10-95915-000-INP. The Urbanization, Poverty, and Health Dynamics (UPHD) research project was funded by the Wellcome Trust (Grant Number GR 07830 M). The Monitoring and assessing the impact of immunization and other childhood interventions, an INDEPTH Network collaboration project was funded by the Danish Development Agency (DANIDA) (DFC Project no 09-09-105SSI). This research was also made possible through the generous funding for the NUHDSS by a number of donors including the Rockefeller Foundation (USA), the Wellcome Trust (UK), the William and Flora Hewlett Foundation (USA), Comic Relief (UK), the Swedish International Development Cooperation (SIDA) and the Bill and Melinda Gates Foundation (USA) and the core funding for APHRC by the William and Flora Hewlett Foundation (Grant\# 2009-40510), and the Swedish International Cooperation Agency (SIDA) (Grant\# 2011-001578).

\section{Author details}

'African Population and Health Research Center, P.O Box 10787 - 00100, Nairobi, Kenya. ${ }^{2}$ University of the Witwatersrand, School of Public Health, 27 St Andrews Road, Johannesburg Parktown 2193, South Africa. ${ }^{3}$ Department of Population Health, Luxembourg Institute of Health, 1A-B, rue Thomas Edison, L-1445 Strassen, Strassen, Luxembourg. ${ }^{4}$ Department of Mathematics and Information sciences, Faculty of Engineering and Environment, Northumbria University, Newcastle upon Tyne, UK.

Received: 9 April 2015 Accepted: 8 October 2015

Published online: 13 October 2015

\section{References}

1. FAO, WFP, IFAD. The state of food insecurity in the World 2012. In: Economic growth is necessary but not sufficient to accelerate reduction of hunger and malnutrition. Rome: FAO; 2012.

2. Cook JT, Frank DA. Food security, poverty, and human development in the United States. Ann N Y Acad Sci. 2008;1 136(1):193-209. doi:10.1196/ annals.1425.001.

3. United Nations Department of Economic and Social Affairs. Sustainable development knowledge platform. 2015. https://sustainabledevelopment.un.org/ ?menu=1300. Accessed 13 October 2015.

4. Cook JT, Frank DA, Berkowitz C, Black MM, Casey PH, Cutts DB, et al. Food insecurity is associated with adverse health outcomes among human infants and toddlers. J Nutr. 2004;134(6):1432-8.

5. Grantham-McGregor S, Cheung YB, Cueto S, Glewwe P, Richter L, Strupp B, et al. Developmental potential in the first 5 years for children in developing countries. Lancet. 2007;369(9555):60-70. doi:10.1016/50140-6736(07)60032-4.

6. Ahmed T, Mahfuz M, Ireen S, Shasmsir AM, Rahman S, Islam MM, et al. Nutrition of children and womein in Bangladesh: trends and directions for the future. J Popul Nutr. 2012;30(1):1-11.

7. Pinstrup-Andersen P, Babinard J. Globalisation and human nutrition: opportunities and risks for poor in developing countries. Afr J Food Nutr Sci. 2001;1:9-18.

8. United Nations Development Programme (UNDP). Africa human development report 2012: towards a food Secure future. Popul Dev Rev. 2013:39(1):172-3. doi:10.1111/j.1728-4457.2013.00584.x.

9. United Nations Children's Fund, World Health Organization, The World Bank. UNICEF-WHO-World Bank joint child malnutrition estimates. UNICEF, New York; WHO, Geneva; The World Bank, Washington, DC; 2012.

10. Kenya National Bureau of Statistics. Kenya demographic and health surveys, 2014: key indicators. Nairobi, Kenya: Kenya National Bureau of Statistics (KNBS)2015; 2015.

11. Fotso JC, Madise N, Baschieri A, Cleland J, Zulu E, Mutua MK, et al. Child growth in urban deprived settings: does household poverty status matter? At which stage of child development? Health Place. 2012;18(2):375-84. doi:10.1016/j.healthplace.2011.12.003.

12. Engle P, Menon P, Haddad L. Care and nutrition: concepts and measurement. World Dev. 1999;27(8):1309-37.

13. Black RE, Allen LH, Bhutta ZA, Caulfield LE, de Onis M, Ezzati M, et al. Maternal and child undernutrition: global and regional exposures and health consequences. Lancet. 2008:371(9608):243-60.

14. Casey PH, Simpson PM, Gossett JM, Bogle ML, Champagne CM, Connell C, et al. The association of child and household food Insecurity with childhood overweight status. Pediatrics. 2006;1 18(5):e1406-13. doi:10.1542/peds.2006-0097.

15. Martorell R. The nature of child malnutrition and its long-term implications. Food Nutr Bull. 1999;20(3):288-92.

16. Jyoti DF, Frangillo EA, Jones SJ. Food insecurity affects school children's academic performance, weight gain, and social skills. J Nutr. 2005;135:2831-9.

17. Prado E, Dewey K. Insight nutrition and brain development in early life, AT\&T Technical Brief, vol. 4. 2012.

18. Thompson R, Nelson C. Developmental science and the media: early brain development. Am Psychol Assoc. 2001;56:5-15.

19. Alaimo K, Olson C, Frangillo EA, Briefel R. Food insufficiency, poverty, and health in U.S. pre-school and school-age children. Am J Public Health. 2001;91:781-6.

20. Vozoris NT, Tarasuk VS. Household food insufficiency is associated with poorer health. J Nutr. 2003;133(1):120-6.

21. Psaki S, Bhutta ZA, Ahmed T, Ahmed S, Bessong P, Islam M, et al. Household food access and child malnutrition: results from the eight-country MAL-ED study. Popul Health Metrics. 2012;10(1):24. doi:10.1186/1478-7954-10-24. 
22. Dubois L, Farmer A, Girard M, Porcherie M. Family food insufficiency is related to overweight among preschoolers'. Soc Sci Med. 2006;63:1503-16.

23. Dubois L, Damion F, Burnier D, Tatone-Tokuda F, Girard M, Gordon-Strachan $\mathrm{G}$, et al. Household food insecurity and childhood overweight in Jamaica and Québec: a gender-based analysis. BMC Public Health. 2011;11:119.

24. Osei A, Pandey P, Spiro D, Nielson J, Shrestha R, Talukder Z, et al. Household food insecurity and nutritional status of children aged 6 to 23 months in Kailali district of Nepal. Food Nutr Bull. 2010;31:4.

25. Beguy D, Elung'ata P, Mberu B, Oduor C, Wamukoya M, Nganyi B, et al. HDSS profile: the Nairobi Urban Health and Demographic Surveillance System (NUHDSS). Int J Epidemiol. 2015. doi:10.1093/ije/dyu251.

26. Zere E, Mclntyre D. Inequiteis in under-five child malnutrion in South Africa. Int J Equity Health. 2003;2:7.

27. UNICEF. The state of the world's children 1998. New York: Oxford University Press; 1998.

28. World Food Summit. Rome declaration on world food security. 1996. http:// www.fao.org/docrep/003/w3613e/w3613e00.HTM . Accessed on 13 October 2013.

29. Radimer KL, Olson C, Campell CC. Development of indicators to access hunger. J Nutr. 1990;120(11):1544-8.

30. Faye O, Baschieri A, Falkingham J, Muindi K. Hunger and food insecurity in Nairobi's slums: an assessment using IRT models. J Urban Health. 2011;88 Suppl 2:S235-54.

31. Tavakol M, Dennick R. Making sence of Cronbach's alpha. Int J Med Educ. 2011;2:23-55. doi:10.5116/ijme.4dfb.8dfd.

32. Filmer D, Pritchett LH. Estimating wealth effects without expenditure data - or tears: an application to educational enrolments in states of India. Demography. 2001;38(1):115-32.

33. Kenya National Bureau of Statistics (KNBS), ICF Macro. Kenya demographic and health survey 2008-09. Calverton: KNBS and ICF Macro; 2010.

34. Ali Naser I, Jalil R, Wan Muda WM, Wan Nik WS, Mohd Shariff Z, Abdullah MR. Association between household food insecurity and nutritional outcomes among children in Northeastern of Peninsular Malaysia. Nutr Res Pract. 2014:8(3):304-11. doi:10.4162/nrp.2014.8.3.304.

35. Dammann K, Smith C. Food-related attitudes and behaviors at home, school, and restaurants: perspectives from racially diverse, urban, lowincome 9- to 13-year-old children in Minnesota. J Nutr Educ Behav. 2010;42(6):389-97.

36. Kimani-Murage EW, Holding PA, Fotso JC, Ezeh AC, Madise N, Kahurani EN, et al. Food security and nutritional outcomes among urban poor orphans in Nairobi, Kenya. J Urban Health. 2011;88 Suppl 2:282-97. doi:10.1007/s11524010-9491-z.

37. Fotso JC. Urban-rural differentials in child malnutrition: trends and socioeconomic correlates in sub-Saharan Africa. Health Place. 2007;13:205-23. doi:10.1016/j.healthplace.2006.01.004

38. Fotso JC. Child health inequities in developing countries: differences across urban and rural areas. Int J Equity Health. 2006;5:9.

39. Kimani-Murage EW, Schofield L, Wekesah F, Mohamed S, Mberu B, Ettarh R, et al. Vulnerability to food insecurity in urban slums: experiences from Nairobi, Kenya. J Urban Health. 2014. doi:10.1007/s11524-014-9894-3.

40. Saaka M, Osman SM. Does household food insecurity affect the nutritional status of preschool children aged 6-36 Months? Int J Popul Res. 2013;2013:12. doi:10.1155/2013/304169.

41. Hannum E, Liu J, Frongillo EA. Poverty, food insecurity and nutritional deprivation in rural China: implications for children's literacy achievement. Int J Educ Dev. 2014;34:90-7. http://dx.doi.org/10.1016/ j.jedudev.2012.07.003.

42. Reis M. Food insecurity and the relationship between household income and children's health and nutrition in Brazil. Health Econ. 2012;21(4):405-27. doi:10.1002/hec.1722.

43. Dinsa GD, Goryakin Y, Fumagalli E, Suhrcke M. Obesity and socioeconomic status in developing countries: a systematic review. Obes Rev. 2012;13(11):1067-79. doi:10.1111/j.1467-789X.2012.01017.x.

44. Townsend MS, Peerson J, Love B, Achterberg C, Murphy SP. Food insecurity is positively related to overweight in women. J Nutr. 2001;131(6):1738-45.

45. Bellera CA, MacGrogan G, Debled M, Lara CT, Brouste V, Mathoulin-Pélissier S. Variables with time-varying effects and the Cox model: some statistical concepts illustrated with a prognostic factor study in breast cancer. BMC Med Res Methodol. 2010;10:20. doi:10.1186/1471-2288-10-20.

46. McIntyre L. Food security: More than a determinant of health. Policy Options. 2003;24(3):46-51.
47. Chilton M, Rose D. A rights-based approach to food insecurity in the United States. Am J Public Health. 2009;99(7):1203-11. doi:10.2105/AJPH.2007.130229.

48. MacAuslan I, Schofield L. Evaluation of Concern Kenya's Korogocho emergency and food security cash transfer initiative. Nairobi: Concern Worldwide and Oxford Policy Management; 2011.

49. African Population and Health Research Center (APHRC). Population and health dynamics in Nairobi's informal settlements: report of the Nairobi cross-sectional slums survey (NCSS) 2012. Nairobi: APHRC; 2014.

\section{Submit your next manuscript to BioMed Central and take full advantage of:}

- Convenient online submission

- Thorough peer review

- No space constraints or color figure charges

- Immediate publication on acceptance

- Inclusion in PubMed, CAS, Scopus and Google Scholar

- Research which is freely available for redistribution 